\title{
Pulse Wave Velocity in Postmenopausal Women
}

\author{
Hiromichi Suzuki ${ }^{a}$ Kazuoki Kondo ${ }^{b}$ \\ aDepartment of Nephrology, Saitama Medical University, Saitama, and byomiuri Clinic, \\ Tokyo, Japan
}

\section{Key Words}

Cardiovascular disease - Osteoporosis · Pulse wave velocity · Menopause · Hormone replacement therapy

\begin{abstract}
Cardiovascular disease (CVD) and osteoporosis are major causes of morbidity and mortality in postmenopausal women. The relationship between atherosclerosis and osteoporosis has been established by studies of the underlying pathophysiological mechanisms and biochemical pathways that seem to overlap in many places. Pulse wave velocity (PWV) is one of the known predictors of cardiovascular and all-cause mortality. Studies indicate that PWV in hypertensive postmenopausal women is increased, and hormone replacement therapy (HRT) attenuates this increase. In addition, recently, many studies have suggested a role for arterial stiffness in the association between CVD and osteoporosis. From these findings, it appears that estrogen deficiency combined with production of inflammatory cytokines plays a role in increased PWV closely associated with CVD and osteoporosis, although the mechanisms of arterial stiffness in postmenopausal women may be more complex. Accordingly, a possible role for PWV as a surrogate marker of CVD as well as osteoporosis in postmenopausal women is discussed in this review. First, menopause leads to increased arterial stiffness with aging in females. Further, epidemiological data evaluating arterial stiffness assessed by PWV provided evidence that most of the established CVD risk factors are determinants of PWV, and these risk factors are increased in patients with CVD. In turn, contrary to expectation, HRT did not always contribute to a lower incidence of CVD in postmenopausal women. By reviewing the current data available, it becomes clear that, at present, the effects of menopause including HRT on PWV remain controversial, and further studies are needed to clarify these associations.

Copyright (C) 2013 S. Karger AG, Basel
\end{abstract}




\section{Introduction}

It is well known that there is a difference between women and men across the life span with respect to the risk and prevalence of cardiovascular disease (CVD) and osteoporosis. With aging, the ratio of men to women regarding the incidence of CVD declines to approximately $2: 1$ between the ages of 65 and 69 years, and to 1:1 by the age of 85 years [1]. The incidence of CVD increases markedly in women after menopause [2]. Moreover, CVD and osteoporosis are major causes of morbidity and mortality in postmenopausal women [3]. Established surrogate markers of early CVD such as intima-media thickness, carotid-femoral pulse wave velocity (PWV) and adjusted augmentation index can be assessed by noninvasive and easily accessible methods, providing information regarding the cardiovascular function and the risk of an asymptomatic individual for future CVD events [4]. PWV is a known indicator and a highly reproducible measure of central arterial stiffness [5]. In addition, it is a predictor of cardiovascular and all-cause mortality [6-8]. Recently, several studies have suggested a role for arterial stiffness in the association between CVD and osteoporosis. Accordingly, in this article we review the current data regarding the role of PWV in both CVD and osteoporosis in postmenopausal women.

\section{Gender Differences in PWV}

Several studies have reported that aging increases arterial stiffness similarly in both genders [9]. However, these studies included patients with hypertension, and it is well known that elevated blood pressure is an important determinant of PWV. In addition, the numbers of subjects in the previous studies were too small for chronological analysis of the influence of age on PWV. Therefore, it is clear that a rigorous conclusion about the influence of age on PWV could not be derived from those studies. Considering these factors, Tomiyama et al. [10] demonstrated that age is a more important determinant of brachial-ankle pulse wave velocity (baPWV) in females than in males, independent of blood pressure variables. Furthermore, baPWV increases in proportion to the square of increase in age starting around the age of 50-60 years in females. These findings suggest that menopause is an important factor influencing arterial stiffness in healthy female subjects. Some studies have demonstrated that estrogen has beneficial effects on arterial stiffness [11]. Tomiyama et al. [10] further proposed that atherosclerotic lesions progress independently in peripheral and central sites [12]. Arterial stiffness has been shown to reflect the change of arterial wall degeneration [5]. In the arterial tree, peripheral sites contain more muscular component and central sites contain more elastic component [13]. Both estrogen and androgen receptors have been demonstrated to be present in vascular smooth muscle cells [14]. Accordingly, it is possible that the influence of age on peripheral and central sites in the arterial tree is different in males and females. Besides, the heart-brachial PWV evaluates peripheral sites in the upper limbs and the baPWV evaluates peripheral sites in the lower limbs and central sites. While the chronological change in baPWV is more marked in females, the heart-brachial PWV is higher in males than in females at all ages. Thus, the augmentation of arterial stiffness with aging might be more prominent in central sites (aorta) and/or peripheral sites in the lower extremities in females.

\section{Impact of Menopause on PWV}

Several studies have examined the association between arterial stiffness and menopause. London et al. [9], based on a cross-sectional study, concluded that menopause augments the age-related increase in arterial stiffness; however, the number of subjects in their study was 
Fig. 1. Correlation between baPWV and age in pre- and postmenopausal women. Broken and solid lines represent regression lines for pre- and postmenopausal women, respectively (reproduced from [18]).

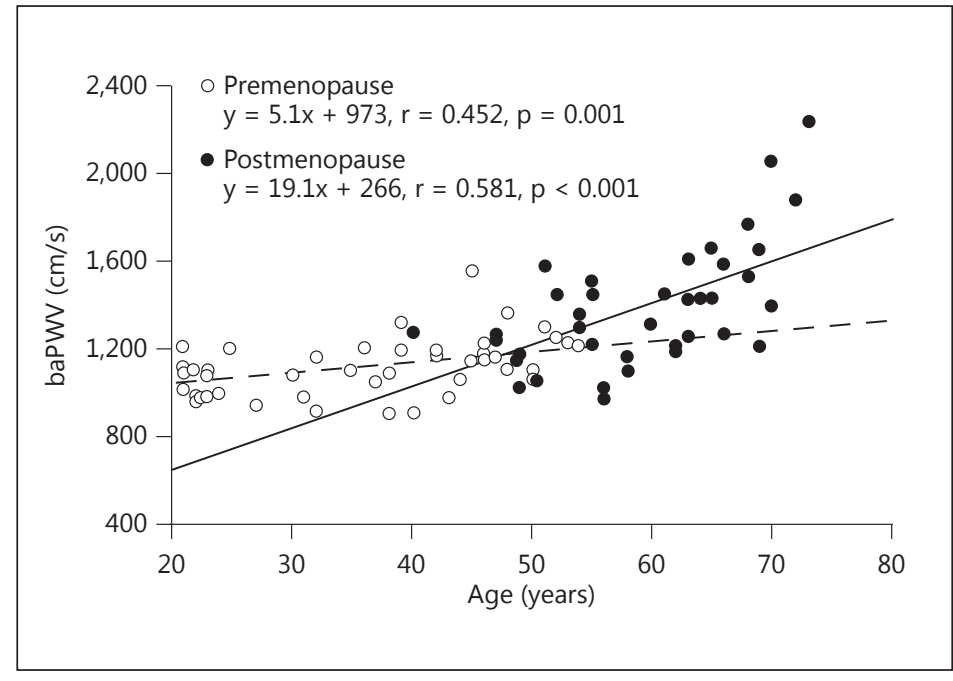

too small. On the other hand, Smulyan et al. [15] reported, again based on a cross-sectional study, that structural changes of the blood vessels, rather than menopause itself, influenced age-related changes in PWV in women; however, they did not specifically consider the influence of menopause in their study. A study by Lebrun et al. [16] that examined a crosssection of postmenopausal women provided evidence that most of the established cardiovascular risk factors are determinants of aortic PWV. An increased PWV is a marker of an increased risk of stroke, coronary heart disease, and death within 10-12 years. Tomiyama et al. [10] reported that the augmentation of arterial stiffness with aging was more prominent in females than in males. They further demonstrated in a cross-sectional study that among many factors including menopausal status, hypertension, diabetes mellitus, hypercholesterolemia, and obesity, a significant relationship existed between menopause and PWV, independent of age and conventional atherosclerotic risk factors [17]. Similar findings showed that although there was a significant difference in baPWV between pre- and postmenopausal women, the mean baPWV of postmenopausal women in their 50 s tended to be higher than that in premenopausal women of the same age. Moreover, the slope of the regression line for baPWV plotted against age was steeper in postmenopausal than in premenopausal women [18] (fig. 1). These findings suggest that menopause causes an augmentation of the agedependent increase in arterial stiffness. Altogether, it is clear that menopause per se may increase aortic stiffness as determined by measuring baPWV.

\section{Mechanisms of Arterial Stiffness in Postmenopausal Women}

Studies have shown that, in parallel with a decreasing PWV in women receiving hormone replacement therapy (HRT), there was a decrease in total and low-density lipoprotein cholesterol in serum. There is evidence of an increase in the expression and secretion of proinflammatory cytokines, interleukin (IL)-1, IL-6, and tumor necrosis factor- $\alpha$ with a reduction in estradiol [19]. Activation of C-reactive protein (CRP) by these cytokines could inhibit the endothelium-dependent vasodilation and synthesis of nitric oxide. Furthermore, inflammation could adversely impact the vascular changes mediated by inflammation that are likely occurring because of a decline in estrogen as menopause progresses [20, 21]. Increases in vessel diameter due to stiffening induced by menopause could lead to an increase in tensile 
stress, which would make the vessel more susceptible to risk factors for increased inflammation [22]. The proatherogenic effect of testosterone is supported by experimental and in vitro studies. Androgen exposure is associated with increased adhesion of mononuclear cells to the vascular endothelium and oxidation of low-density lipoprotein by mononuclear cellderived macrophages [23]. Testosterone impairs the endothelium-dependent vasorelaxation in hypercholesterolemic rabbits [24]. Furthermore, testosterone has been associated with a decrease of the elastin-to-collagen ratio in aortic smooth muscle cell culture.

Recent data have indicated that lower dehydroepiandrosterone sulfate (DHEAS) levels may be related to higher cardiovascular mortality in postmenopausal women with CVD risk factors undergoing coronary angiography for suspected ischemia [25]. Similar findings were reported by Creatsa et al. [26] who showed that lower levels of DHEAS are associated with increased arterial stiffness, because DHEAS has been widely associated with an antiproliferative effect by inhibition of important apoptosis pathways such as the 3-phosphoinositidedependent kinase pathway/nuclear factor of activated T-cells/hypoxia-inducible-factor axis [27].

Regnault et al. [28] demonstrated that there is a link between vascular stiffening and several procoagulant and anticoagulant factors in postmenopausal women. Moreover, an important finding which is not explained by age per se is the positive relationship between circulating free tissue factor pathway inhibitor (TFPI) and arterial stiffness or pulse pressure (brachial or carotid). Circulating von Willebrand factor (vWF) is also associated with PWV, as previously reported, but the correlation disappeared after adjustment for pulse pressure.

The geometric and hemodynamic properties of a cylindrical arterial vessel are relatively easy to determine using noninvasive measurements. The vascular wall acts as a container of blood coagulation factors, which are classified either as procoagulants such as vWF or as anticoagulants such as TFPI [29]. In addition, it has been previously established that increased circulating vWF is consistently associated with endothelial dysfunction [30]. Although high TFPI might also indicate endothelial dysfunction [31], recent work has suggested that TFPI levels in medial vascular smooth muscle cells may serve primarily to prevent arterial thrombosis and even intimal hyperplasia [32]. Therefore, an increase in arterial stiffness is associated with both changes in vascular wall status and the presence of a hypercoagulable state [15]. Altogether, the findings suggest that the vascular wall is a major contributor to the thrombotic response, in part via the production of vWF and TFPI [33].

\section{Effect of HRT on PWV}

The expected effect of HRT to interrupt or delay the development of cardiovascular disorders in postmenopausal women has been confirmed in clinical studies [34]. However, despite circumstantial evidence showing the advantages of HRT in various clinical settings, the role of HRT in the prevention of CVD has not yet been clearly defined. Rajkumar et al. [11] demonstrated improved vascular compliance after HRT, showing simultaneously that it is associated with lower PWV in large elastic arteries. These observations were confirmed in a randomized study by Giraud et al. [35]. Also Nagai et al. [36] demonstrated that HRT has beneficial effects by reducing arterial stiffness by $21 \%$ compared with subjects not receiving HRT. These results are not in accordance with the results of Angerer et al. [37] and Teede et al. [38] who did not find improved vascular compliance after 1 year of HRT in their study populations except for women who smoked. This might relate to the fact that smoking reduces carotid arterial distensibility by about 33\% [39]. Moreover, smoking activates sympathetic activity, increases vascular smooth muscle tension, and alters endothelial-dependent vasodilation. In a cross-sectional study of 18 women undergoing HRT and 16 controls, Tanaka et al. 
[40] noted no differences in PWV between the two groups. The study by Waddell et al. [41] showed a significant fall in femoro-dorsalis PWV 4 weeks after HRT cessation. Previously, Blacher et al. [42] reported that changes in PWV and pulse pressure were of similar magnitude in women with and without HRT also taking angiotensin-converting enzyme inhibitors. Similarly, Sumino et al. [43] demonstrated that transdermal estradiol therapy, but not oral conjugated equine estrogen (CEE) therapy, may have antiatherosclerotic effects by improving arterial stiffness; however, it was speculated that the reductions in baPWV may have been related to the direct effect of estrogen, but not to the decrease in estrogen-induced vascular inflammatory markers. In overweight postmenopausal women with type 2 diabetes, the aorto-femoral PWV remained unchanged after 6 months of oral CEE plus oral medroxyprogesterone acetate [44]. On the other hand, 12 months of continuous transdermal hormone substitution with $17 \beta$-estradiol (50 $\mathrm{\mu g}$ /day) and norethisterone acetate decreased the carotid-femoral PWV in postmenopausal women with arterial hypertension [45]. Gangar et al. [46] showed that 22 weeks of continuous transdermal estradiol (50 $\mu \mathrm{g} /$ day) plus cyclic medroxyprogesterone acetate $(10 \mathrm{mg} /$ day $)$ reduced the pulsatility index of the internal carotid artery in normotensive postmenopausal women. Although there are differences in the dosage, type, and duration of the estrogen or progesterone treatments, the study populations, and the methods used to measure PWV between these studies and the study by Sumino et al. [43], other studies support the findings of the latter authors. Oral CEE therapy had no effects on arterial stiffness but caused a reduction in monocyte chemoattractant protein-1 (MCP-1), cell adhesion molecules, total cholesterol and low-density lipoprotein cholesterol levels, and an increase in high-sensitivity CRP, matrix metalloproteinase-9, triglycerides, and high-density lipoprotein cholesterol levels in postmenopausal women. In contrast, transdermal estradiol therapy reduced arterial stiffness and the levels of MCP- 1 and cell adhesion molecules but had no effect on lipids, high-sensitive CRP, and matrix metalloproteinase- 9 levels in postmenopausal women. Westendorp et al. [47] demonstrated that 24 months of continuous CEE $(0.625 \mathrm{mg} /$ day $)$ plus cyclic norgestrel $(0.15 \mathrm{mg} /$ day $)$ did not change the distensibility or compliance of the common carotid artery in premenopausal women. Although many studies investigating the effects of HRT have been reported, it is clear that, at present, the effects of HRT on PWV as well as on CVD and osteoporosis remain controversial.

\section{Effects of Hypertensive Therapy on PWV in Postmenopausal Women}

Hayoz et al. [48] compared the effects of hypertensive therapy with either a calcium channel blocker (CCB) or an angiotensin receptor blocker (ARB) on PWV in postmenopausal women and found that both regimens reduced PWV to a similar degree after 38 weeks of treatment despite differences in central blood pressure lowering. These findings suggest that the effect of ARB on PWV is mediated through nonhemodynamic effects. Recently, Suzuki et al. [49] compared the effects of antihypertensive therapy of a combination in ARB plus a diuretic with an ARB plus a CCB on PWV in 55 postmenopausal women (average age $58 \pm 6$ years) for 5 years. Neither of the groups showed a difference in mean blood pressure before and after treatment (before treatment: ARB + CCB 150/82 $\pm 21 / 11 \mathrm{~mm}$ Hg and ARB + diuretic $151 / 81 \pm 21 / 8 \mathrm{~mm} \mathrm{Hg}$ and at the end of treatment: ARB + CCB 135/81 $\pm 17 / 8 \mathrm{~mm} \mathrm{Hg}$ and $\mathrm{ARB}+$ diuretic $133 / 80 \pm 24 / 11 \mathrm{~mm} \mathrm{Hg}$, compared with the treatment before; $\mathrm{p}<0.05$ ). The mean PWV of the group receiving ARB + diuretic was 1,513 $\pm 241 \mathrm{~cm} / \mathrm{s}$ before treatment and $1,575 \pm 289 \mathrm{~cm} / \mathrm{s}$ after treatment, and that of the ARB + CCB group was 1,526 $\pm 241 \mathrm{~cm} / \mathrm{s}$ before treatment and 1,546 $\pm 273 \mathrm{~cm} / \mathrm{s}$ after treatment. There were no significant differences between the two groups. Ratios of blood pressure normalization of the ARB + CCB and ARB + diuretic groups were 92 and 89\%, respectively [49]. Moreover, the effects of these two anti- 
hypertensive treatments on PWV did not produce any significant difference, indicating that both combination therapies are effective for treatment of hypertensive postmenopausal women.

\section{Role of PWV in Postmenopausal Women with White-Coat Hypertension}

Whether white-coat hypertension is benign or not still remains controversial. Pickering [50] analyzed 739 patients followed prospectively for an average duration of 5 years. The author found that the prevalence of cardiovascular morbid events was $2.1 \%$ in patients with white-coat hypertension and $4.4 \%$ in those with sustained hypertension. In postmenopausal women, irregularity and cessation of menstrual cycle induce psychological disturbances as well as physiological instability that affect blood pressure measurement producing the so-called white-coat hypertension. In clinical practice, it remains unknown whether or not white-coat hypertension can be considered a benign condition [51]. Moreover, although the majority of studies concluded that white-coat hypertension was not associated with a significantly increased prevalence of target organ damage [52], some studies found an increased left ventricular (LV) mass in subjects with white-coat hypertension compared with normotensive controls [53]. Rudd et al. [54] reported that the prevalence of LV hypertrophy was significantly higher in subjects with white-coat hypertension than in normotensive subjects. In women who are diagnosed as having hypertension irrespective of white-coat effects or not, it is important to find LV hypertrophy or PWV increases. Based on these data, Suzuki et al. [55] evaluated arterial stiffness by using PWV in postmenopausal women who had blood pressure measurement both in an office setting and at home in conjunction with LV geometry [56]. Kuwajima et al. [56] and Sokolow et al. [57] observed that patients with no evidence of target organ damage had a greater difference between the clinic and home pressure measurements than patients with target organ damage. In agreement with previous findings, Suzuki et al. [55] reported that the LV mass index was significantly associated with systolic blood pressure at home but not in the office, indicating that self-reported blood pressure measurements are useful for the management of blood pressure in hypertensive patients. Moreover, there was a significant correlation between PWV and systolic blood pressure in postmenopausal women. PWV showed a greater increase with age independently of any increase in mean arterial pressure [58] (table 1). From these data, it appears that in postmenopausal women, adverse effects on the heart and arteries are not just caused by the elevated resistance and pressure per se, but by arterial stiffening and higher pulsatile stresses that result from elevated mean pressure. These findings have an important implication for the treatment of hypertension in postmenopausal women. The blood pressure at home, intensity of PWV, and index of LV mass should be measured and the strategy for antihypertensive treatment should be planned based on these data. It is therefore concluded that the combination of selfmonitoring of blood pressure, echocardiographic data, and PWV can be powerful indicators for the treatment of hypertension in postmenopausal women.

\section{Close Association between Osteoporosis and Arterial Stiffness}

In women, the incidence of osteoporosis increases markedly after menopause, with approximately 1 in 4 women over the age of 50 years exhibiting osteoporosis (National Osteoporosis Foundation 2007, National Institute of Health, Washington, D.C., USA; Osteoporosis Canada 2007, Toronto, Ont., Canada). Osteoporosis and atherosclerosis are chronic degenerative diseases with a high incidence in postmenopausal women. Some of the pathophysio- 
Suzuki et al.: Pulse Wave Velocity in Postmenopausal Women

Table 1. Office and home blood pressure and PWV and LV mass index in hypertensive and white-coat hypertensive postmenopausal women

\begin{tabular}{lcc}
\hline & $\begin{array}{l}\text { Hypertensive } \\
(\mathrm{n}=24)\end{array}$ & $\begin{array}{l}\text { White-coat } \\
\text { hypertensive }(\mathrm{n}=20)\end{array}$ \\
\hline Office SBP, mm Hg & $167.9 \pm 4.8$ & $170.7 \pm 6.5$ \\
Office DBP, mm Hg & $88.5 \pm 7.0$ & $91.8 \pm 9.1$ \\
Home SBP, mm Hg & $144 \pm 7$ & $123.1 \pm 4.3$ \\
Home DBP, mm Hg & $84.3 \pm 3.8$ & $76.3 \pm 7.5$ \\
PWV, m/s & $17.6 \pm 1.9$ & $16.0 \pm 1.9$ \\
LV mass index & $121 \pm 7$ & $120 \pm 8$ \\
\hline
\end{tabular}

Values are mean \pm SEM.

SBP = Systolic blood pressure; DBP = diastolic blood pressure.

logical mechanisms and underlying biochemical pathways of these two diseases seem to overlap. Risk factors for vascular disease, such as dyslipidemia, systemic arterial hypertension, diabetes mellitus, and hyperhomocysteinemia, have been associated with a higher incidence of low bone mass density (BMD). The increase in serum levels of some cytokines during the atherosclerotic process is involved in the inflammatory etiology of both atherosclerosis and osteoporosis. The bone resorptive potential of monocytes was found to directly correlate with serum IL-1, IL-6, and tumor necrosis factor- $\alpha$ levels in postmenopausal women. In addition, these cytokines stimulate the proliferation and differentiation of osteoclast precursors [59] and are also well known to be directly involved in the severity of atherosclerosis [60]. According to these findings, it is obvious that inflammatory processes induced by these cytokines are the link between osteoporosis and atherosclerosis. Besides, several mechanisms of vascular injury have been proposed for homocysteine, including a reduction in nitric oxide, endothelial dysfunction, and increased platelet aggregation. These factors produce proliferation of vascular smooth muscle cells and osteoclast precursors.

In relation to these common pathophysiological pathways, several previous studies examining the association between arterial stiffness and bone status in Japanese populations have reported conflicting results [61]. Two studies showed an independent correlation between baPWV and low BMD, whereas a third study did not. Mangiafico et al. [62] demonstrated that postmenopausal women with osteoporosis present with an increased augmentation index, central aortic pressures, and a higher carotid-femoral PWV. Epidemiological data suggest that estrogen deficiency is a risk factor for both CVD and osteoporosis [63]. Bone and arteries are target tissues for estrogen. Estrogen receptors have been demonstrated on osteoblasts [64], osteoclasts [65], vascular endothelial cells, and smooth muscle cells [66]. HRT in postmenopausal women increases BMD [67] and reduces carotid-femoral PWV [45]. In general, estrogen may be an important factor in the relationship between bone mass and arterial stiffness. However, based on the findings of Sumino et al. [68], the serum estradiol level is not significantly correlated with BMD or PWV, suggesting that estrogen alone cannot explain the relationship between bone mass and arterial stiffness. Sanada et al. [69] reported that postmenopausal women with osteoporosis have impaired endothelial function in resistance arteries of the forearm, which could be responsible for an increase in serum angiotensin-converting enzyme activity and a decrease in serum concentrations of nitrite/nitrate. These factors may play an important role in the pathogenesis of both osteoporosis and arterial stiffness. Sumino et al. [68] demonstrated that age and baPWV were significantly higher in the group with osteoporosis than in the normal BMD group, and that age was significantly positively correlated with baPWV in the group with osteoporosis but not in the normal BMD group. Furthermore, these authors, by using multivariate regression analysis, demonstrated 
that baPWV was also significantly negatively correlated with BMD, but not with age. Therefore, baPWV might be higher in postmenopausal women with osteoporosis than in those with a normal bone mass, which is independent of age.

In summary, from this review, it becomes clear that, at present, the effects of menopause including HRT on PWV remain controversial, and that further studies are needed to clarify these associations.

\section{References}

1 Eaker ED, Chesebro JH, Sacks FM, Wenger NK, Whisnant JP, Winston M: Cardiovascular disease in women. Circulation 1993;88:1999-2009.

- 2 Witteman JC, Grobbee DE, Kok FJ, Hofman A, Valkenburg HA: Increased risk of atherosclerosis in women after the menopause. BMJ 1989;298:642-644.

3 von der Recke P, Hansen MA, Hassager C: The association between low bone mass at the menopause and cardiovascular mortality. Am J Med 1999;106:273-278.

- 4 Stein JH, Korcarz CE, Post WS: Use of carotid ultrasound to identify subclinical vascular disease and evaluate cardiovascular disease risk: summary and discussion of the American Society of Echocardiography consensus statement. Prev Cardiol 2009;12:34-38.

5 Asmar R, Benetos A, Topouchian J, Laurent P, Pannier B, Brisac AM, et al: Assessment of arterial distensibility by automatic pulse wave velocity measurement. Validation and clinical application studies. Hypertension 1995;26:485-490.

- 6 Laurent S, Boutouyrie P, Asmar R, Gautier I, Laloux B, Guize L, et al: Aortic stiffness is an independent predictor of all-cause and cardiovascular mortality in hypertensive patients. Hypertension 2001;37:1236-1241.

- 7 Shoji T, Emoto M, Shinohara K, Kakiya R, Tsujimoto Y, Kishimoto H, et al: Diabetes mellitus, aortic stiffness, and cardiovascular mortality in end-stage renal disease. J Am Soc Nephrol 2001;12:2117-2124.

- 8 Blacher J, Safar ME, Pannier B, Guerin AP, Marchais SJ, London GM: Prognostic significance of arterial stiffness measurements in end-stage renal disease patients. Curr Opin Nephrol Hypertens 2002;11:629-634.

- 9 London GM, Guerin AP, Pannier B, Marchais SJ, Stimpel M: Influence of sex on arterial hemodynamics and blood pressure. Role of body height. Hypertension 1995;26:514-519.

-10 Tomiyama H, Yamashina A, Arai T, Hirose K, Koji Y, Chikamori T, et al: Influences of age and gender on results of noninvasive brachial-ankle pulse wave velocity measurement - a survey of 12,517 subjects. Atherosclerosis 2003;166:303-309.

11 Rajkumar C, Kingwell BA, Cameron JD, Waddell T, Mehra R, Christophidis N, et al: Hormonal therapy increases arterial compliance in postmenopausal women. J Am Coll Cardiol 1997;30:350-356.

12 Avolio A: Genetic and environmental factors in the function and structure of the arterial wall. Hypertension $1995 ; 26: 34-37$.

13 Hayward CS, Kelly RP, Collins P: The roles of gender, the menopause and hormone replacement on cardiovascular function. Cardiovasc Res 2000;46:28-49.

14 Fujimoto R, Morimoto I, Morita E, Sugimoto H, Ito Y, Eto S: Androgen receptors, 5 alpha-reductase activity and androgen-dependent proliferation of vascular smooth muscle cells. J Steroid Biochem Mol Biol 1994;50:169174.

15 Smulyan H, Asmar RG, Rudnicki A, London GM, Safar ME: Comparative effects of aging in men and women on the properties of the arterial tree. J Am Coll Cardiol 2001;37:1374-1380.

-16 Lebrun CE, van der Schouw YT, Bak AA, de Jong FH, Pols HA, Grobbee DE, et al: Arterial stiffness in postmenopausal women: determinants of pulse wave velocity. J Hypertens 2002;20:2165-2172.

17 Zaydun G, Tomiyama H, Hashimoto H, Arai T, Koji Y, Yambe M, et al: Menopause is an independent factor augmenting the age-related increase in arterial stiffness in the early postmenopausal phase. Atherosclerosis 2006;184:137-142.

18 Takahashi K, Miura S, Mori-Abe A, Kawagoe J, Takata K, Ohmichi M, et al: Impact of menopause on the augmentation of arterial stiffness with aging. Gynecol Obstet Invest 2005;60:162-166.

19 Pfeilschifter J, Köditz R, Pfohl M, Schatz H: Changes in proinflammatory cytokine activity after menopause. Endocr Rev 2002;23:90-119.

20 Yasmin, McEniery CM, Wallace S, Mackenzie IS, Cockcroft JR, Wilkinson IB: C-reactive protein is associated with arterial stiffness in apparently healthy individuals. Arterioscler Thromb Vasc Biol 2004;24:969-974.

-21 Mattace-Raso FU, van der Cammen TJ, van der Meer IM, Schalekamp MA, Asmar R, Hofman A, et al: C-reactive protein and arterial stiffness in older adults: the Rotterdam Study. Atherosclerosis 2004;176:111-116.

$\checkmark 22$ Wildman RP, Colvin AB, Powell LH, Matthews KA, Everson-Rose SA, Hollenberg S, et al: Associations of endogenous sex hormones with the vasculature in menopausal women: the Study of Women's Health Across the Nation (SWAN). Menopause 2008;15:414-421. 
23 McCrohon JA, Jessup W, Handelsman DJ, Celermajer DS: Androgen exposure increases human monocyte adhesion to vascular endothelium and endothelial cell expression of vascular cell adhesion molecule-1. Circulation 1999;99:2317-2322.

-24 Hutchison SJ, Sudhir K, Chou TM, Sievers RE, Zhu BQ, Sun YP, et al: Testosterone worsens endothelial dysfunction associated with hypercholesterolemia and environmental tobacco smoke exposure in male rabbit aorta. J Am Coll Cardiol 1997;29:800-807.

25 Shufelt C, Bretsky P, Almeida CM, Johnson BD, Shaw LJ, Azziz R, et al: DHEA-S levels and cardiovascular disease mortality in postmenopausal women: results from the National Institutes of Health - National Heart, Lung, and Blood Institute (NHLBI)-sponsored Women's Ischemia Syndrome Evaluation (WISE). J Clin Endocrinol and Metab 2010;95:4985-4992.

-26 Creatsa M, Armeni E, Stamatelopoulos K, Rizos D, Georgiopoulos G, Kazani M, et al: Circulating androgen levels are associated with subclinical atherosclerosis and arterial stiffness in healthy recently menopausal women. Metabolism 2012;61:193-201.

-27 Dumas de la Roque E, Savineau JP, Bonnet S: Dehydroepiandrosterone: a new treatment for vascular remodeling diseases including pulmonary arterial hypertension. Pharmacol Ther 2010;126:186-199.

28 Regnault V, Perret-Guillaume C, Kearney-Schwartz A, Max JP, Labat C, Louis H, et al: Tissue factor pathway inhibitor: a new link among arterial stiffness, pulse pressure, and coagulation in postmenopausal women. Arterioscler Thromb Vasc Biol 2011;31:1226-1232.

29 Mosnier LO, Zlokovic BV, Griffin JH: The cytoprotective protein C pathway. Blood 2007;109:3161-3172.

-30 Spiel AO, Gilbert JC, Jilma B: von Willebrand factor in cardiovascular disease: focus on acute coronary syndromes. Circulation 2008;117:1449-1459.

-31 Mitchell CT, Kamineni A, Palmas W, Cushman M: Tissue factor pathway inhibitor, vascular risk factors and subclinical atherosclerosis: the Multi-Ethnic Study of Atherosclerosis. Atherosclerosis 2009;207:277-283.

-32 Mackman N, Taubman MB: Does tissue factor expression by vascular smooth muscle cells provide a link between C-reactive protein and cardiovascular disease? Arterioscler Thromb Vasc Biol 2008;28:601-603.

33 Mann KG, Brummel-Ziedins K, Orfeo T, Butenas S: Models of blood coagulation. Blood Cells Mol Dis 2006;36: 108-117.

-34 Grodstein F, Stampfer MJ, Colditz GA, Willett WC, Manson JE, Joffe M, et al: Postmenopausal hormone therapy and mortality. N Engl J Med 1997;336:1769-1775.

-35 Giraud GD, Morton MJ, Wilson RA, Burry KA, Speroff L: Effects of estrogen and progestin on aortic size and compliance in postmenopausal women. Am J Obstet Gynecol 1996;174:1708-1717; discussion 1717-1718.

-36 Nagai Y, Earley CJ, Kemper MK, Bacal CS, Metter EJ: Influence of age and postmenopausal estrogen replacement therapy on carotid arterial stiffness in women. Cardiovasc Res 1999;41:307-311.

37 Angerer P, Kothny W, Stork S, von Schacky C: Hormone replacement therapy and distensibility of carotid arteries in postmenopausal women: a randomized, controlled trial. J Am Coll Cardiol 2000;36:1789-1796.

-38 Teede HJ, Liang YL, Shiel LM, McNeil JJ, McGrath BP: Hormone replacement therapy in postmenopausal women protects against smoking-induced changes in vascular structure and function. J Am Coll Cardiol 1999;34: 131-137.

-39 Kool MJ, Hoeks AP, Struijker Boudier HA, Reneman RS, Van Bortel LM: Short- and long-term effects of smoking on arterial wall properties in habitual smokers. J Am Coll Cardiol 1993;22:1881-1886.

40 Tanaka H, DeSouza CA, Seals DR: Arterial stiffness and hormone replacement use in healthy postmenopausal women. J Gerontol A Biol Sci Med Sci 1998;53:M344-M346.

41 Waddell TK, Rajkumar C, Cameron JD, Jennings GL, Dart AM, Kingwell BA: Withdrawal of hormonal therapy for 4 weeks decreases arterial compliance in postmenopausal women. J Hypertens 1999;17:413-418.

-42 Blacher J, Raison J, Amah G, Schiemann AL, Stimpel M, Safar ME: Increased arterial distensibility in postmenopausal hypertensive women with and without hormone replacement therapy after acute administration of the ACE inhibitor moexipril. Cardiovasc Drugs Ther 1998;12:409-414.

-43 Sumino H, Ichikawa S, Kasama S, Takahashi T, Kumakura H, Takayama Y, et al: Different effects of oral conjugated estrogen and transdermal estradiol on arterial stiffness and vascular inflammatory markers in postmenopausal women. Atherosclerosis 2006;189:436-442.

-44 Samaras K, Hayward CS, Sullivan D, Kelly RP, Campbell LV: Effects of postmenopausal hormone replacement therapy on central abdominal fat, glycemic control, lipid metabolism, and vascular factors in type 2 diabetes: a prospective study. Diabetes Care 1999;22:1401-1407.

45 Kawecka-Jaszcz K, Czarnecka D, Olszanecka A, Rajzer M, Jankowski P: The effect of hormone replacement therapy on arterial blood pressure and vascular compliance in postmenopausal women with arterial hypertension. J Hum Hypertens 2002;16:509-516.

-46 Gangar KF, Vyas S, Whitehead M, Crook D, Meire H, Campbell S: Pulsatility index in internal carotid artery in relation to transdermal oestradiol and time since menopause. Lancet 1991;338:839-842.

47 Westendorp IC, de Kleijn MJ, Bots ML, Bak AA, Planellas J, Coelingh Bennink HJ, et al: The effect of hormone replacement therapy on arterial distensibility and compliance in perimenopausal women: a 2-year randomised trial. Atherosclerosis 2000;152:149-157.

48 Hayoz D, Zappe DH, Meyer MA, Baek I, Kandra A, Joly MP, et al: Changes in aortic pulse wave velocity in hypertensive postmenopausal women: comparison between a calcium channel blocker versus angiotensin receptor blocker regimen. J Clin Hypertens (Greenwich) 2012;14:773-778. 
49 Suzuki H, Dogi M, Takenaka T, Inoue T, Watabe Y, Kikuta T (eds): Effects of combination of antihypertensive agents on blood pressure in postmenopausal women. 34th Annual Scientific Meeting of the Japanese Society of Hypertension, Ustunomiya, Japan, October 20-22, 2011.

50 Pickering TG: Ambulatory Monitoring and Blood Pressure Variability. London, Science Press, 1991.

51 Perloff D, Sokolow M, Cowan R: The prognostic value of ambulatory blood pressure. JAMA 1983;249:27932798.

52 White WB, Schulman P, McCabe EJ, Dey HM: Average daily blood pressure, not office blood pressure, determines cardiac function in patients with hypertension. JAMA 1989;261:872-873.

53 Cardillo C, De Felice F, Campia U, Folli G: Psychophysiological reactivity and cardiac end-organ changes in white-coat hypertension. Hypertension 1993;21:836-844.

54 Rudd P, Price MG, Graham LE, Beilstein BA, Tarbell SJ, Bacchetti P, Frontmann SP: Consequences of worksite hypertension screening: differential changes in psychosocial function. Am J Med 1986;80:853-860.

55 Suzuki H, Kanno Y, Kobayashi K, Okada H, Nakamoto H: Pulse pressure is an important factor in determination of the choice of antihypertensive drugs in postmenopausal women. 19th Scientific Meeting of the International Society of Hypertension, Prague, Czech Republic, 2002.

-56 Kuwajima I, Miyao M, Uno A, Suzuki Y, Matsushita S, Kuramoto K: Diagnostic values of electrocardiography and echocardiography for white-coat hypertension in the elderly. Am J Cardiol 1994;73:1232-1234.

57 Sokolow M, Perloff D, Cowan R: Contribution of ambulatory blood pressure to the assessment of patients with mild to moderate elevations of office blood pressure. Cardiovasc Rev Rep 1980;1:295-303.

58 Nichols WW, O'Rourke MF: Ascending aortic pressure waves; in Nichols WW, O'Rourke MF (eds): McDonald's Blood Flow in Arteries: Theoretical, Experimental and Clinical Principles. London, Edward Amold, 1998, pp 457-476.

59 Miyaura C, Kusano K, Masuzawa T, Chaki O, Onoe Y, Aoyagi M, et al: Endogenous bone-resorbing factors in estrogen deficiency: cooperative effects of IL-1 and IL-6. J Bone Miner Res 1995;10:1365-1373.

60 Libby P: Inflammation in atherosclerosis. Nature 2002;420:868-874.

61 Hirose K-i, Tomiyama H, Okazaki R, Arai T, Koji Y, Zaydun G, et al: Increased pulse wave velocity associated with reduced calcaneal quantitative osteo-sono index: possible relationship between atherosclerosis and osteopenia. J Clin Endocrinol Metab 2003;88:2573-2578.

62 Mangiafico RA, Alagona C, Pennisi P, Parisi N, Mangiafico M, Purrello F, et al: Increased augmentation index and central aortic blood pressure in osteoporotic postmenopausal women. Osteoporos Int 2008;19:49-56.

63 Kalin MF, Zumoff B: Sex hormones and coronary disease: a review of the clinical studies. Steroids 1990;55: 330-352.

64 Eriksen EF, Colvard DS, Berg NJ, Graham ML, Mann KG, Spelsberg TC, et al: Evidence of estrogen receptors in normal human osteoblast-like cells. Science 1988;241:84-86.

65 Oursler MJ, Pederson L, Fitzpatrick L, Riggs BL, Spelsberg T: Human giant cell tumors of the bone (osteoclastomas) are estrogen target cells. Proc Natl Acad Sci USA 1994;91:5227-5231.

66 Mendelsohn ME, Karas RH: The protective effects of estrogen on the cardiovascular system. N Engl J Med 1999; 340:1801-1811.

67 Felson DT, Zhang Y, Hannan MT, Kiel DP, Wilson PW, Anderson JJ: The effect of postmenopausal estrogen therapy on bone density in elderly women. N Engl J Med 1993;329:1141-1146.

68 Sumino H, Ichikawa S, Kasama S, Takahashi T, Kumakura H, Takayama Y, et al: Elevated arterial stiffness in postmenopausal women with osteoporosis. Maturitas 2006;55:212-218.

69 Sanada M, Taguchi A, Higashi Y, Tsuda M, Kodama I, Yoshizumi M, et al: Forearm endothelial function and bone mineral loss in postmenopausal women. Atherosclerosis 2004;176:387-392. 